\title{
Early CT features of COVID-19 pneumonia, association with patients' age and duration of presenting complaint
}

\author{
Reem M. EL Kady ${ }^{1,2^{*}}$ (D), Hosam A. Hassan ${ }^{1}$, Tareef S. Daqqaq ${ }^{2}$, Rania Makboul ${ }^{3}$ and Hanan Mosleh Ibrahim ${ }^{4,5}$
}

\begin{abstract}
Background: Coronavirus disease (COVID-19) is a respiratory syndrome with a variable degree of severity. Imaging is a vital component of disease monitoring and follow-up in coronavirus pulmonary syndromes. The study of temporal changes of CT findings of COVID-19 pneumonia can help in better understanding of disease pathogenesis and prediction of disease prognosis. In this study, we aim to determine the typical and atypical CT imaging features of COVID-19 and discuss the association of typical CT imaging features with the duration of the presenting complaint and patients' age.

Results: The lesions showed unilateral distribution in $20 \%$ of cases and bilateral distribution in $80 \%$ of cases. The lesions involved the lower lung lobes in $30 \%$ of cases and showed diffuse involvement in $58.2 \%$ of cases. The lesions showed peripheral distribution in $74.5 \%$ of cases. The most common pattern was multifocal ground glass opacity found in $72.7 \%$ of cases. Atypical features like cavitation and pleural effusion can occur early in the disease course. There was significant association between increased number of the lesions, bilaterality, diffuse pattern of lung involvement and older age group ( $\geq 50$ years old) and increased duration of presenting complaint ( $\geq 4$ days). There was significant association between crazy-paving pattern and increased duration of presenting complaint. No significant association could be detected between any $\mathrm{CT}$ pattern and increased patient age.

Conclusion: The most common CT feature of COVID-19 was multifocal ground glass opacity. Atypical features like cavitation and pleural effusion can occur early in the course of the disease. Our cases showed more extensive lesions with bilateral and diffuse patterns of distribution in the older age group and with increased duration of presenting complaint. There was a significant association between crazy-paving pattern and increased duration of presenting complaint. No significant association could be detected between any CT pattern and increased patient age.
\end{abstract}

Keywords: COVID-19, Typical CT imaging features, Atypical CT imaging features

\section{Background}

On December 31, 2019, many cases with pneumonia of unidentified cause have been reported in Wuhan, China [1]. On January 7, 2020, coronavirus disease 2019 (COVID-19) was confirmed as the cause of these reported cases [2]. With rapid worldwide viral

\footnotetext{
*Correspondence: reem.elkady@aun.edu.eg

'Department of Radiology, Assiut University, Assiut, Egypt

${ }^{2}$ Department of Radiology, Taibah University, Medina, Saudi Arabia

Full list of author information is available at the end of the article
}

transmission, a global pandemic was announced by WHO on January 30, 2020 [3]. Coronavirus disease (COVID-19) is a respiratory syndrome with a variable degree of severity, ranging from a mild upper respiratory tract illness to severe pneumonia and acute respiratory distress [4]. The analysis of genetic sequence discloses that COVID-19 belongs to the $\beta$-coronavirus genus, with a $79.0 \%$ nucleotide identity to severe acute respiratory syndrome coronavirus (SARS-CoV) and $51.8 \%$ identity to Middle East respiratory syndrome coronavirus

\section{Springer Open}

(อ The Author(s). 2021 Open Access This article is licensed under a Creative Commons Attribution 4.0 International License, which permits use, sharing, adaptation, distribution and reproduction in any medium or format, as long as you give appropriate credit to the original author(s) and the source, provide a link to the Creative Commons licence, and indicate if changes were made. The images or other third party material in this article are included in the article's Creative Commons licence, unless indicated otherwise in a credit line to the material. If material is not included in the article's Creative Commons licence and your intended use is not permitted by statutory regulation or exceeds the permitted use, you will need to obtain permission directly from the copyright holder. To view a copy of this licence, visit http://creativecommons.org/licenses/by/4.0/. 
(MERS-CoV) [5]. The standard of reference for confirming COVID-19 infection depends on microbiological tests such as real-time reverse-transcriptase polymerase chain reaction (rt RT-PCR). However, these tests may not be available in an emergency setting or convey a high rate of false-negative results. The addition of an imaging tool as computed tomography (CT) to the patient diagnostic workup could be helpful in certain clinical scenario [6]. Besides, imaging is a vital component of disease progression monitoring and follow-up in coronavirus-related pulmonary syndromes [7]. The study of temporal changes in the CT findings of COVID-19 pneumonia and the effect of patient age on the imaging features can help in understanding the disease pathogenesis and prediction of disease prognosis. Recent studies have discussed the common $\mathrm{CT}$ imaging features of COVID-19 pneumonia; however, only few studies discussed the association of different CT imaging features with patients' age and the duration of present complaint. In this study, we aim to determine the typical and atypical CT imaging features of COVID-19 pneumonia and discuss the association of common $\mathrm{CT}$ imaging features with patients' age and the duration of the presenting complaint.

\section{Methods}

This is an institutional review board approved study. The informed consent was waived. A retrospective review of the hospital information system was done for all confirmed cases of COVID-19 with available chest CT done early in the course of the disease (within 10 days duration from the beginning of the symptoms). In our center, all suspected cases underwent plain X-ray chest examination, and then only cases with positive or equivocal findings in the chest radiograph were directed to perform CT chest examination. All cases were confirmed by respiratory samples tested by real-time reverse-transcriptase-polymerase chain reaction rt (RTPCR). All cases with chronic cardiac or thoracic illness were excluded. Available clinical data including patient age, patient's presenting complaint, duration of the complaint, and clinical index score (mild, moderate, severe) were recorded. The patients were classified according to age into two groups ( $<50$ and $\geq 50$ years old). The patients were classified according to the duration of complaint into $\leq 4$ days and $>4$ days duration. Data collection was done for a three-consecutive-month duration with a final cohort of 110 cases was identified for our study.

\section{CT protocol}

All included cases underwent CT examination using Philips CT scanner (ingenuity core 64 specification). The examination was done in a supine position with the head advanced. The examination was done during the end of inspiration after breath-hold. Contrast media was administrated only in one case. The used parameters were as follow: Number of detectors 32, tube voltage $120 \mathrm{kV}$, $\mathrm{mAs} 300$, beam collimation width $64 \times 0.625$ pitch 0.789 , gantry tilt 0 , field of view 350 . Axial and multiplanar reconstruction images were done.

\section{Image analysis}

Imaging findings were reviewed by 2 radiologists with more than 15 years' experience. Both readers interpret CT images independently and blindly to clinical information. The CT lesions were evaluated for unilateral or bilateral distribution, lobar involvement (upper, middle, lower, or diffuse) and central or peripheral involvement. CT findings were classified into typical or common patterns (multi focal ground-glass opacity (GGO), GGO with superimposed consolidation, consolidation predominant, linear opacities, peribronchial thickening, and crazy paving), atypical or less common patterns (single GGO, air bronchogram, pulmonary nodule, cavity formation, tree in bud sign, fibrotic changes), and other findings, e.g., vascular enlargement, vascular thrombosis, pleural thickening, pleural effusion, and lymphadenopathy.

Imaging findings were recorded and correlated with available clinical data.

\section{Statistical analysis}

Data were analyzed using SPSS version 21. Inter-rater agreement was calculated using Cohen's kappa coefficient $(j)$ which is calculated as follows: $j=(p 0$ pe $) /(1 \mathrm{pe})$, where $\mathrm{p} 0$ is the observed proportion of agreement and pe is the expected proportion of agreement. Descriptive statistics were displayed using frequencies and percentages for categorical variables and mean \pm standard deviation for continuous variables. Chi-square test was performed to investigate the association of patients' radiological findings with the patients' age (less than 50 years and 50 years or more) and duration of presenting complaint ( 4 days or less, more than 4 days). Statistical significance was set at a $\mathrm{P}$ value $<0.05$.

\section{Results}

A total number of 110 patients, 87 males (79.1\%) and 23 females (20.9\%) with confirmed COVID-19 infection were retrospectively enrolled in our study. All patients were adults with an age range from 18 to 83 years old (with mean age $=43.5$ years old). Seventy-three patients (66.4\%) were less than 50 years old and 37 patients (33.6\%) were 50 years old or older. The main complaints of most of our patients were fever, cough, sore throat, and body aches. Twenty-five (22.7\%) patients had dyspnea or shortness of breath. The duration of complaint 
at the time of presentation ranged from 2 to 7 days (with a mean duration of 3.7 days). The duration of presenting complaint was 4 days or less in 86 patients (78.2\%) and more than 4 days in 24 patients $(21.8 \%)$. The clinical index was low in $2(1.8 \%)$ patients, moderate in 35 (31.8\%) patients, and high in $73(66.4 \%)$ patients.

As regard the interrater reliability in this study, there was an almost perfect agreement in the assessment of CT images between the two readers (0.93). CT showed abnormal findings in all 110 cases. As regards the distribution of the lesions, the lesions showed unilateral distribution in $22(20 \%)$ cases and bilateral distribution in $88(80 \%)$ cases. For lobar involvement, the lesions were mainly involving upper lung lobes in 10 (9.1\%) cases, middle lung lobe and lingula in $3(2.7 \%)$ cases, lower lung lobes in 33 (30\%) cases, and showed diffuse involvement in $64(58.2 \%)$ cases. The lesions showed perihilar distribution in only one case $(0.9 \%)$, peripheral distribution in $82(74.5 \%)$ cases, and diffuse central and peripheral in 27 (24.5\%) cases (Table 1).

The most common pattern was multifocal groundglass opacity found in $80(72.7 \%)$ cases (Fig. 1), while single ground-glass opacity was found only in $2(1.8 \%)$ cases (Fig. 2). Mixed GGO with consolidation was identified in 27 (24.5\%) cases and predominant consolidation in $8(7.3 \%)$ cases (Fig. 3). Pulmonary nodules are detected in only $2(1.8 \%)$ cases and cavitary lesions in 3 $(2.7 \%)$ cases. Linear opacities were identified in 45 (40.9\%) cases, peribronchial thickening in 20 (18.2\%) cases, and crazy paving in $10(9.1 \%)$ cases (Fig. 4), air bronchogram sign in $5(4.5 \%)$ cases, and tree in bud sign in $1(0.9)$ case. Focal pleural thickening and pleural effusion were identified in $2(1.8 \%)$ and $5(4.5 \%)$ cases, respectively (Fig. 5). Vascular enlargement was identified in $18(16.4 \%)$ cases with only one case $(0.9 \%)$ showed thrombosis of the right main pulmonary artery. No hilar or mediastinal adenopathy was identified in our cases.

Table 1 Lesions distribution in the study cohort

\begin{tabular}{lll}
\hline Distribution & Frequency & Percentage \\
\hline Unilateral/bilateral & 22 & \\
Unilateral & 88 & $20 \%$ \\
Bilateral & & $80 \%$ \\
Craniocaudal/lobar & 10 & \\
Upper & 3 & $9.1 \%$ \\
Middle & 33 & $2.7 \%$ \\
Lower & 64 & $30 \%$ \\
Diffuse & & $58.2 \%$ \\
Transverse & 1 & \\
Central/perihilar & 82 & $0.9 \%$ \\
Peripheral & 27 & $74.5 \%$ \\
Diffuse & & $24.5 \%$ \\
\hline
\end{tabular}

All identified CT patterns are shown in Table 2.

As regards association of common CT pattern of COVID-19 with duration of presenting complaint, there was positive association between number of the lesions and bilateral involvement of the lung with the duration of presenting complaint. The peripheral distribution of the lesions was associated with the short duration of presenting complaint $(<4$ days) while diffuse pattern of distribution was associated with a relatively longer duration of presenting complaint ( $\geq 4$ days). As regard the association of typical imaging lesions with the duration of presenting complaint, the crazy-paving pattern was detected in $(6 / 24) 25 \%$ of patients with duration of presenting complaint $>4$ days while was detected in $(4 / 86)$ $4.7 \%$ of patients with duration of presenting complaint $\leq$ 4 days implying a significant association between crazypaving pattern and increased duration of presenting complaint $(\mathrm{p}$ value $=0.002)$. No significant association could be detected between the other typical CT features of COVID-19 pneumonia and the duration of presenting complaint.

As regards association of common CT pattern of COVID-19 with patients' age, there was an association of bilaterality of the lesions and diffuse lung involvement with the older age group ( $\geq 50$ years old). Our cases showed more extensive lesions in older age group $(\geq 50$ years old) than younger age group $(<50$ years old $)$. No significant association could be detected of any typical CT pattern with increased patient age. The associations between common CT pattern detected in our study with duration of presenting complaint and patients' age are shown in Tables 3 and 4 respectively.

\section{Discussion}

CT imaging has a vital role in the diagnosis and management of patients with COVID-19 infection. It allows objective evaluation of the lung lesions, which provides a better understanding of the disease pathogenesis [8].

In general, CT findings of viral pneumonia are diverse and usually affected by the immune status of the host and the underlying pathophysiology of the viral pathogen [9]. Upon entering the pulmonary cells, coronaviruses cause cell damage and pathological changes through direct cytotoxic effects and immunopathogenic effects. These changes are characterized by diffuse alveolar damage (DAD), interstitial mononuclear inflammatory infiltrates, hyaline membrane disease, and desquamation consistent with acute respiratory distress syndrome (ARDS) [10].

Most types of viral pneumonia show bilateral distribution with multiple lung lobes involvement [7]. The lesions in our study showed bilateral distribution in $80 \%$ of cases, and unilateral distribution in $20 \%$ of cases. For craniocaudal involvement, the lesions were mainly 

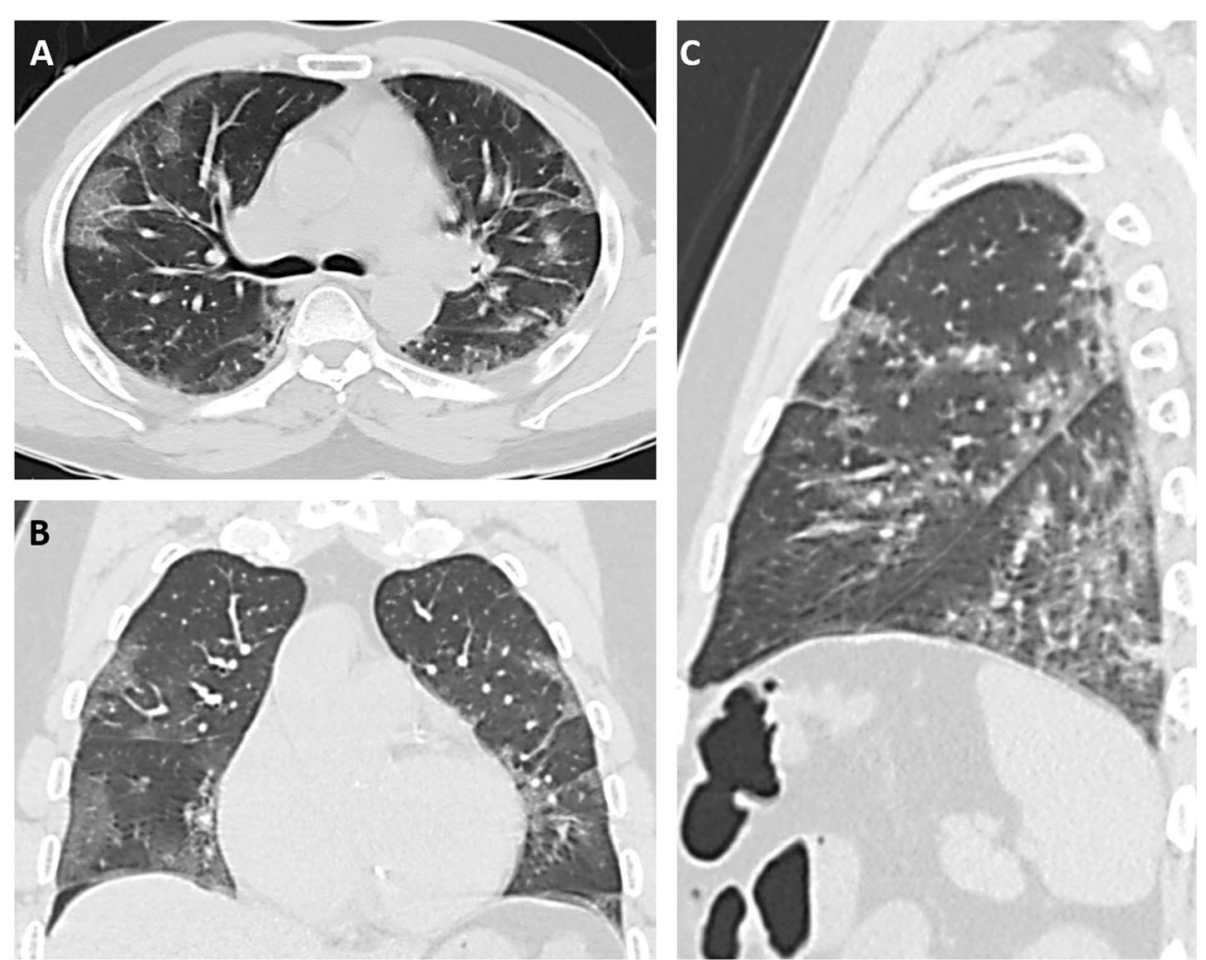

Fig. 1 Non-contrast CT of a 42-year-old male with fever, sore throat, and shortness of breath, rt RT-PCR +VE, (A-C): A, axial; B, coronal; and C, sagittal non-contrast CT scan lung window show bilateral multifocal peripheral and pleural-based ground glass opacity with linear opacities and interlobular thickening

involving the upper lung lobes in $9.1 \%$ of cases, the middle lung lobe, and lingula in $2.7 \%$ of cases, the lower lung lobes in $30 \%$ cases, and showed diffuse involvement in $58.2 \%$ of cases. The lesions showed perihilar distribution in only one case $(0.9 \%)$, peripheral distribution in $74.5 \%$ of cases, and diffuse central and peripheral in $24.5 \%$ cases. Our results as regards lesion distribution are in line with the previous studies $[6,7,11-19]$. The bilateral peripheral basal distribution which is often seen in many viral pulmonary diseases could be explained by the small size of pathogenic microorganism particles and its brisk way to reach peripheral tissue and attack the alveolar epithelium.
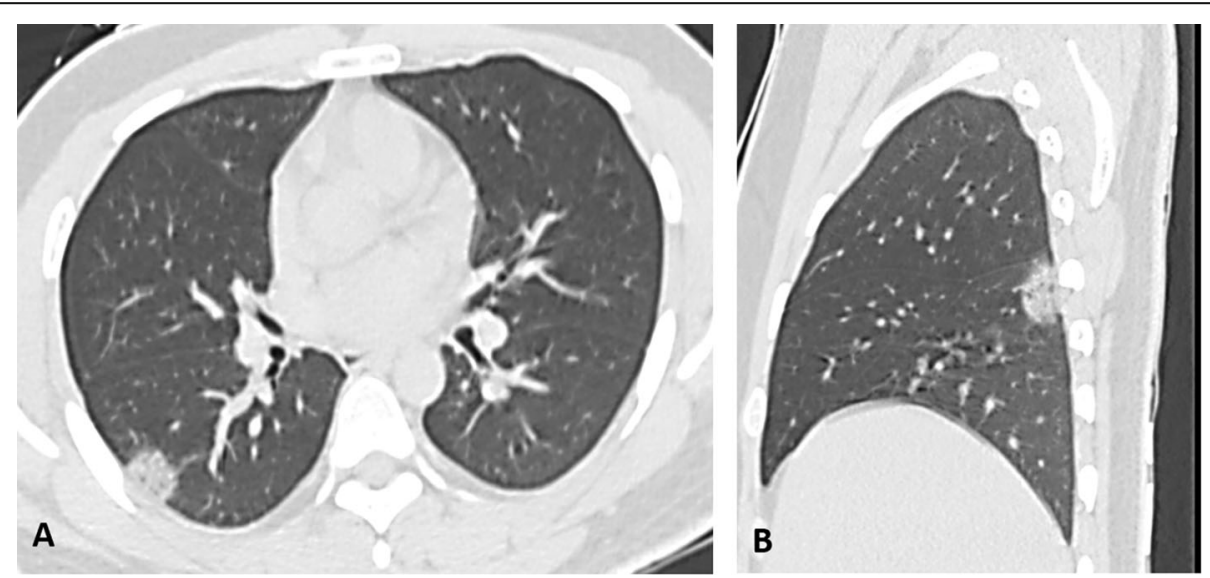

Fig. 2 Non-contrast CT of a 36-year-old male with fever, sore throat, and body ache, rt RT-PCR +VE (A and B): A, axial and $\mathbf{B}$, sagittal non-contrast CT scan in lung window show peripheral single ground glass opacity in the apical segment of the right lower lobe 


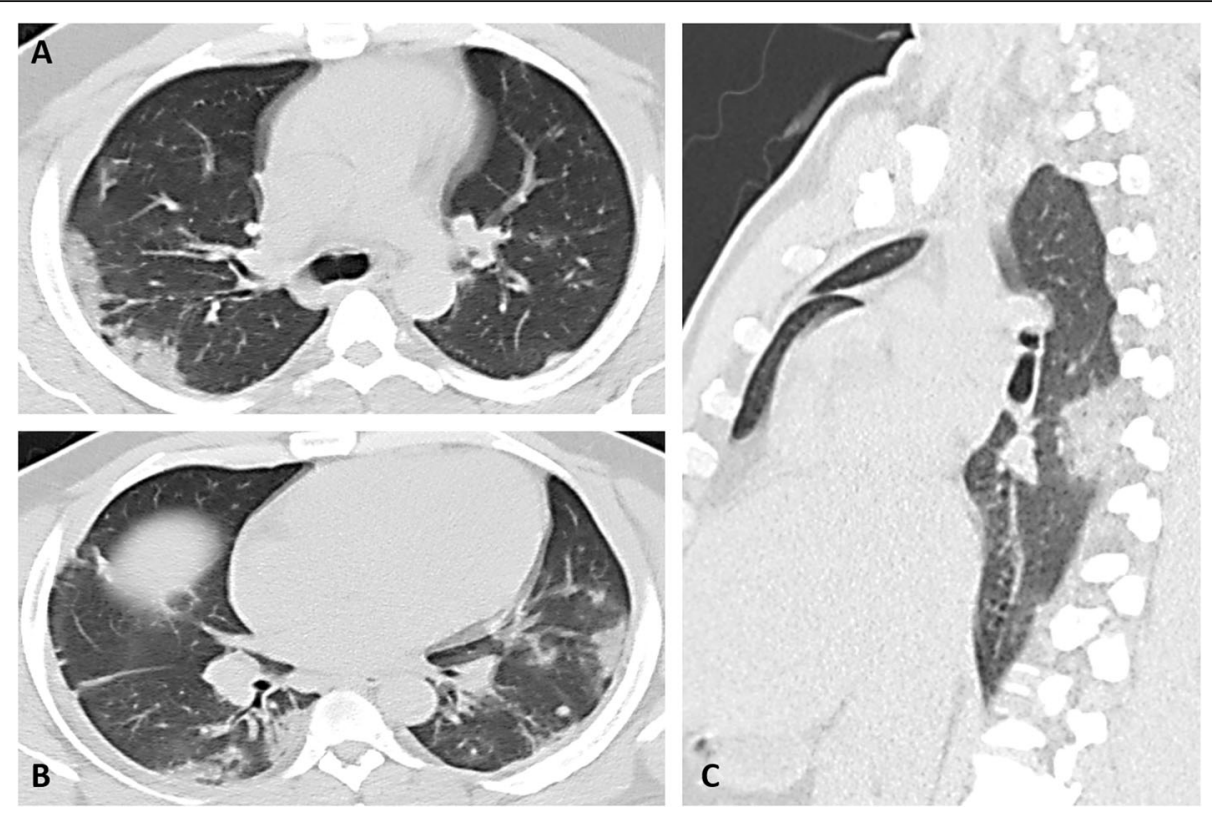

Fig. 3 Non-contrast CT of a 52-year-old male with fever and shortness of breath, rt RT-PCR $+V E(\mathbf{A}-\mathbf{C})$ : $\mathbf{A}$ and $\mathbf{B}$ axial, and $\mathbf{C}$ sagittal non-contrast CT scan lung window show bilateral multiple subpleural areas of consolidation associated with linear opacities and pleural thickening

Based on previous reports, the most frequently observed $\mathrm{CT}$ features with coronaviruses affection are diffuse airspace opacities which present as GGO, consolidation, or mixed GGO and consolidation $[9,20-$ 23]. The pathological basis of the airspace opacities in viral pneumonia is diffuse alveolar damages including intra-alveolar edema, fibrin, and variable cellular infiltrates with a hyaline membrane that is usually present early in the course of coronaviruses affection $[9,21]$. In a study done by Henckel et al. for 14 confirmed cases of COVID-19 with antemortem CT and autopsy correlation, the histopathological observations of airspace opacities were consistent with diffuse alveolar damage associated with capillary dilatation and congestion [24].
They attributed consolidation and bronchial wall thickening to superimposed acute bronchopneumonia.

In our study on confirmed cases of COVID-19, the most common pattern was multifocal ground glass opacity found in $72.7 \%$ of our cases while single ground glass opacity was found only in $1.8 \%$. Mixed GGO with consolidation was identified in $24.5 \%$ of the cases and predominant consolidation in $7.3 \%$. Associated bronchial wall thickening was observed in $18.2 \%$ of cases. The lesions' shape varied from round to irregular or confluent patches.

Our findings as regards typical CT features of COVID19 are matching the other recently published reports about COVID-19 imaging [6, 15, 17-19, 24-26].
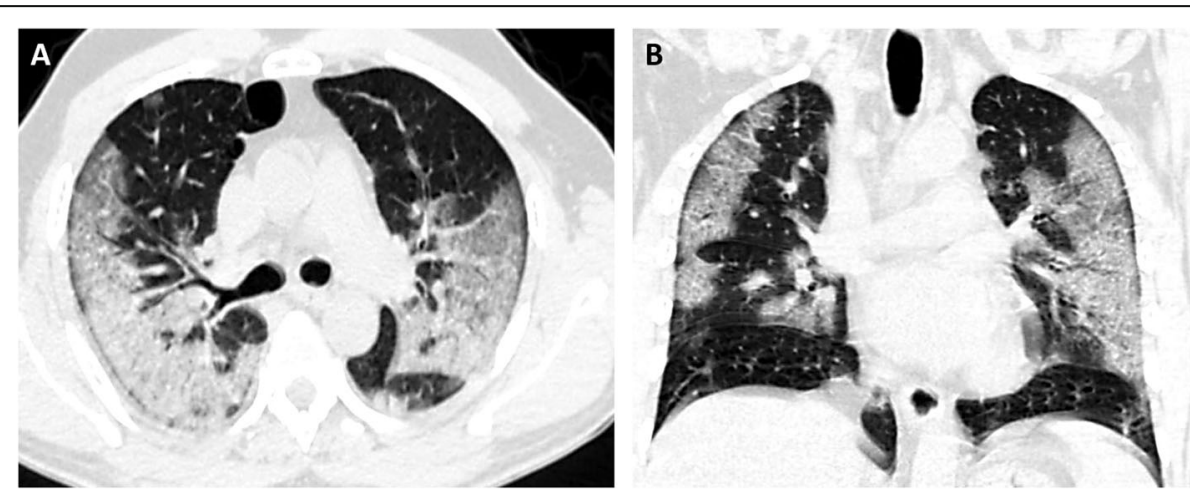

Fig. 4 Non-contrast CT done 6 days after initial complaint of a 68-year-old male with high grade fever and tachypnea, rt RT-PCR +VE. (A, B): A, axial and $\mathbf{B}$, coronal non-contrast CT scan lung window show bilateral peripheral ground glass density with thickened interlobular and intralobular lines (crazy-paving pattern) involving upper, middle lobes, and lingula 

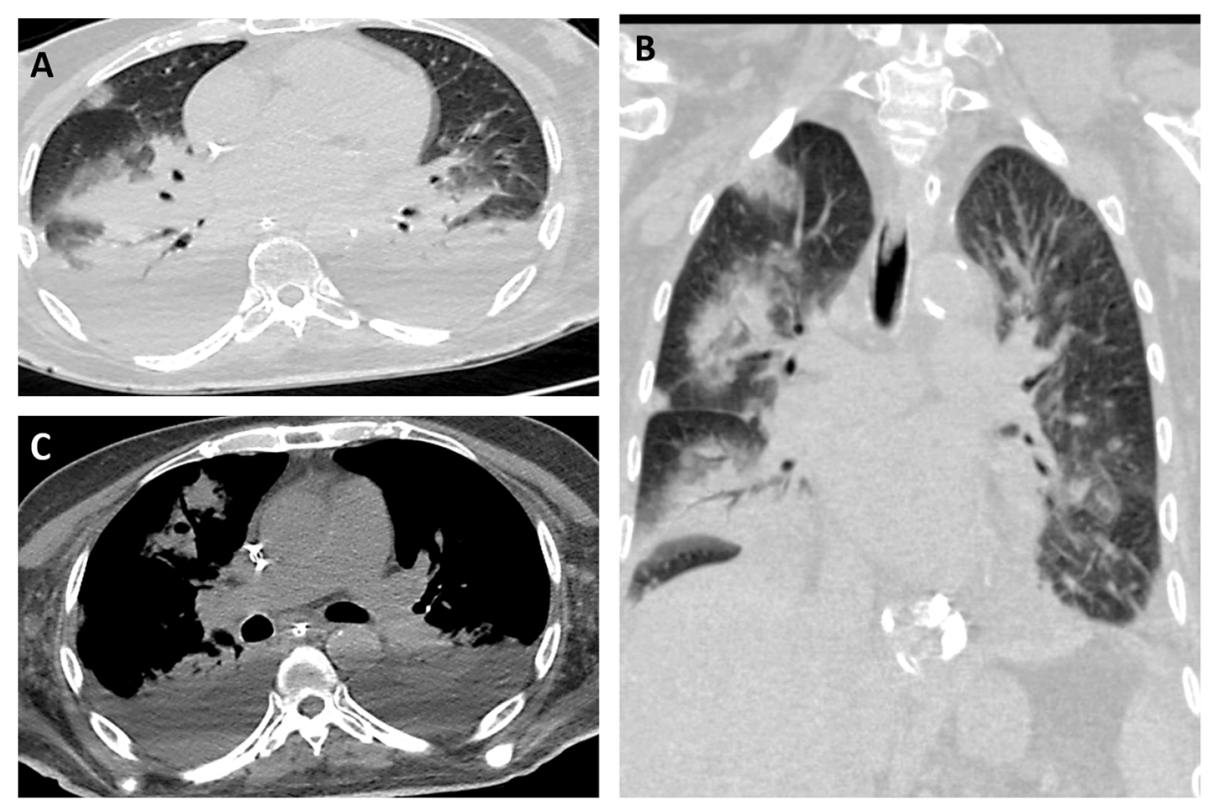

Fig. 5 Non-contrast CT done 5 days after initial complaint of a 60-year-old male with fever, cough, body aches, and shortness of breath. rt RT-PCR $+\mathrm{ve}(\mathbf{A}-\mathbf{C})$ : $\mathbf{A}$, axial and $\mathbf{B}$, coronal lung window and $\mathbf{C}$, axial mediastinal window show bilateral perivascular consolidation (organizing pneumonia pattern) with air bronchogram sign involving both middle and lower lobes with bilateral pleural effusion

Table 2 Different CT imaging findings

\begin{tabular}{lll}
\hline & Frequency & Percentage \\
\hline Common patterns & & \\
Multifocal ground glass & 80 & $72.7 \%$ \\
Mixed GGO with consolidation & 27 & $24.5 \%$ \\
Consolidation predominant pattern & 8 & $7.3 \%$ \\
Linear opacities & 45 & $40.9 \%$ \\
Peribronchial wall thickening & 20 & $18.2 \%$ \\
Crazy-paving pattern & 10 & $9.1 \%$ \\
Less common patterns & & \\
Single ground glass opacity & 2 & $1.8 \%$ \\
Pulmonary nodules & 2 & $1.8 \%$ \\
Cavitary lesions & 3 & $2.7 \%$ \\
Air bronchogram sign & 5 & $4.5 \%$ \\
Tree in bud sign & 1 & $0.9 \%$ \\
Fibrotic changes & 0 & $0 \%$ \\
Other findings & & \\
Focal pleural thickening & 2 & $1.8 \%$ \\
Pleural effusion & 5 & $4.5 \%$ \\
Vascular enlargement & 18 & $16.4 \%$ \\
Vascular thrombosis & 1 & $0.9 \%$ \\
Hilar or mediastinal adenopathy & 0 & 0 \\
\hline
\end{tabular}

With the progression of the disease, the congestion of alveolar septal capillaries and exudation of the fluid into the interstitium cause interstitial septal thickening with linear opacities. Thickened interlobular and intralobular lines in combination with a ground glass pattern are called a crazy-paving pattern. In our study, we included CT exams done within 10 days from the first complaint. Linear opacities and thickening of interstitial septa were observed in $40 \%$ of our cases and crazy-paving pattern was observed in $9.1 \%$ of cases.

Atypical CT features of COVID-19 are not discussed in depth in most of the previous studies. The atypical imaging features of COVID-19 reported by previous studies include tree in bud and centrilobular nodule, cavitation, vascular thrombosis, predominant perihilar ground-glass opacity, pleural thickening and effusion, pneumothorax, and mediastinal or hilar adenopathy [27-29].

The incidence of pulmonary nodules in COVID-19 as reported by previous studies is ranging from 3 to $13 \%$ [28]. In our study, we had two cases that showed pulmonary nodules $(1.8 \%)$. The nodules were associated with other typical findings in both cases. Lung cavitation is an uncommon finding in COVID-19 pneumonia and usually seen in the late stage [30]. Based on autopsy reports, the cavitation in COVID-19 pneumonia is usually caused by diffuse alveolar damage, intra-alveolar hemorrhage, and parenchymal necrosis [31, 32]. We had 3 cases of lung cavitation in our study (2.7\%) with all detected within short duration less than 4 days. 
Table 3 The association between common CT pattern with duration of presenting complaint

\begin{tabular}{|c|c|c|c|c|c|}
\hline \multirow[t]{2}{*}{ Common CT pattern } & \multicolumn{2}{|c|}{ Duration $\leq \mathbf{4}$ days $(n)$} & \multicolumn{2}{|c|}{ Duration $>4$ days $(\mathrm{n})$} & \multirow{2}{*}{$\begin{array}{l}P \\
\text { valu }\end{array}$} \\
\hline & No & Perc.\# & No & Perc.\# & \\
\hline Multifocal ground glass & 61 & $70.9 \%$ & 19 & $79.2 \%$ & 0.423 \\
\hline Mixed GGO with consolidation & 21 & $24.4 \%$ & 6 & $25.0 \%$ & 0.953 \\
\hline Consolidation predominant pattern & 8 & $9.3 \%$ & 0 & $0.0 \%$ & 0.121 \\
\hline Linear opacities & 34 & $39.5 \%$ & 11 & $45.8 \%$ & 0.579 \\
\hline Bronchial wall thickening & 17 & $19.8 \%$ & 3 & $12.5 \%$ & 0.414 \\
\hline Crazy-paving pattern & 4 & $4.7 \%$ & 6 & $25.0 \%$ & 0.002 \\
\hline
\end{tabular}

Perc.\# percentage within duration group

Statistical significance was set at a $P$ value $<0.05$

Pleural effusion is relatively rare in cases of viral infection. A study by Shi et al. indicated that the prevalence of pleural effusion varies depending on the stage of the disease. They reported a prevalence of $13 \%$ in the third week of illness [15]. Another study suggested that the presence of pleural effusion is a poor prognostic indicator for COVID-19 patients [33]. We had 5 cases with pleural effusion in our study (4.5\%) and two cases of pleural thickening (1.8\%). The amount of pleural effusion was mild to moderate, 4 of them showed associated predominant consolidation, and one was associated with a mixed pattern of GGO and consolidation. Since we excluded cases with other comorbidities from our cohort, pleural effusion in our cases can be attributed to COVID-19 infection or superimposed bacterial infection. All the cases with pleural effusion in our study presented within 4 days after the presenting complaint and 3 of them were older than 50 years old.

Intravascular microthrombi were noticed in patients with COVID-19, and the combination of DAD and thrombosis is associated with rapid deterioration of clinical conditions in severe COVID-19 cases [34]. In our study, vascular dilatation was detected in 18 cases and pulmonary embolism was detected in one case. The increased incidence of pulmonary embolism in cases of COVID-19 could be attributed to the cytokine storm

Table 4 The association between common CT pattern with patients' age

\begin{tabular}{|c|c|c|c|c|c|}
\hline \multirow[t]{2}{*}{ Common CT pattern } & \multicolumn{2}{|c|}{$\begin{array}{l}\text { Age }<50 \\
(n=73)\end{array}$} & \multicolumn{2}{|c|}{$\begin{array}{l}\text { Age } \geq 50 \\
(n=37)\end{array}$} & \multirow[t]{2}{*}{$\begin{array}{l}P \\
\text { value }\end{array}$} \\
\hline & No & Perc. $^{*}$ & No & Perc. $^{*}$ & \\
\hline Multifocal ground glass & 48 & $65.8 \%$ & 32 & $86.5 \%$ & 0.24 \\
\hline Mixed GGO with consolidation & 19 & $26.0 \%$ & 8 & $21.6 \%$ & 0.648 \\
\hline Consolidation predominant pattern & 5 & $6.8 \%$ & 3 & $8.1 \%$ & 0.810 \\
\hline Linear opacities & 28 & $38.4 \%$ & 17 & $45.9 \%$ & 0.539 \\
\hline Bronchial wall thickening & 14 & $23.3 \%$ & 6 & $8.1 \%$ & 0.076 \\
\hline Crazy-paving pattern & 4 & $5.5 \%$ & 6 & $16.2 \%$ & 0.083 \\
\hline
\end{tabular}

Perc.* percentage within age group

Statistical significance was set at a $P$ value $<0.05$ which causes a release of proinflammatory cytokines that predispose to coagulopathy [35].

The study of temporal changes in the CT findings of COVID-19 pneumonia can help in understanding the disease pathogenesis and prediction of disease prognosis. A study done by Pan et al. revealed that chest CT showed the most extensive disease almost 10 days after symptom onset [14]. Previous studies indicated that the lesions were limited to single or multiple areas and were distributed along the sub-pleural areas in the early phase of the disease. With disease progression, the lesions increased in number and extended gradually from the periphery to the center of the lung [17]. In our study, there was a positive association between the number of lesions and bilateral involvement of the lung with the duration of presenting complaint. In addition, the peripheral distribution of the lesions was associated with a short duration of presenting complaint $(<4$ days $)$ while diffuse pattern of distribution was associated with a relatively longer duration of presenting complaint ( $\geq 4$ days). As regard the association between typical imaging lesions and duration of presenting complaint, no significant association could be detected between multifocal GGO, predominant consolidation, mixed pattern, or linear opacities and the duration of presenting complaint. The later results are non-concordant with the findings reported by Pan et al. [14]. They found that pulmonary consolidation is rare in the early stages of COVID-19 and increased with the progression of the disease. We cannot argue phases of disease progression as all CT scans included in our study were done relatively earlier in the disease course; however, we confirm that all typical findings can occur in the early stage. The crazypaving pattern showed a positive association with increased duration of presenting complaint ( $\mathrm{p}$ value $=$ 0.002). All CT exams showing crazy-paving pattern were done after 5 days from the initial complaint. This finding is consistent with the reported findings in previous studies $[15,17-19,25,29]$.

Based on concurrent literature, older age, and coexisting comorbidities might be risk factors for the poor 
prognosis of COVID-19 patients [36]. In our study, we found an association between bilateral lesion distribution and diffuse lung involvement with the older age group ( $\geq 50$ years old). Our cases showed more extensive lesions in the older age group ( $\geq 50$ years old) than the younger age group ( $<50$ years old). This finding is matching the results reported by Chan et al. [37]. On the other hand, no significant association could be detected in our study between typical CT patterns and increased patient age. This contradicts what was reported by $\mathrm{Li}$ et al. that younger patients tended to have GGO while older patients tended to have more pulmonary consolidation. They admitted the presence of consolidation as a sign of a bad prognosis in elderly patients [17].

\section{Conclusion}

The most common CT feature of COVID-19 was multifocal ground glass opacity. Atypical features like cavitation and pleural effusion can occur early in the course of the disease. Our cases showed more extensive lesions with bilateral and diffuse patterns of distribution in the older age group and with increased duration of presenting complaint. There was a significant association between crazy-paving pattern and increased duration of presenting complaint. No significant association could be detected between any $\mathrm{CT}$ pattern and increased patient age.

\section{Abbreviations}

COVID-19: Coronavirus disease 2019; rt RT-PCR: Real-time reversetranscriptase polymerase chain reaction; $\mathrm{CT}$ : Computed tomography; GGO: Ground glass opacity; ACE2: Angiotensin-converting enzyme 2; DAD: Diffuse alveolar damage; ARDS: Acute respiratory distress syndrome

\section{Acknowledgements}

Not applicable.

\section{Authors' contributions}

R M K: Design of the study, data analysis, manuscript drafting and revision, and manage publication (corresponding author).

$\mathrm{H} \mathrm{A} \mathrm{H}$ : Design of the study, data collection, data analysis, and manuscript revision.

T S D: Design of the study, data analysis, and manuscript revision.

R M: Manuscript drafting and revision.

H M I: Design of the study, statistical analysis, and manuscript revision.

The authors read and approved the final manuscript.

\section{Funding}

This research did not receive any specific grant from funding agencies in the public, commercial, or not-for-profit sectors.

\section{Availability of data and materials}

The datasets used and/or analyzed during the current study are available on reasonable request.

\section{Declarations}

\section{Ethics approval and consent to participate}

This study has been approved by the ethical committee of Faculty of Medicine, Taibah University, KSA. The approval number is 007-1442. An informed written consent was waived as it is a retrospective study.
Consent for publication

Not applicable

\section{Competing interests}

The authors declare that they have no competing interests.

\section{Author details}

${ }^{1}$ Department of Radiology, Assiut University, Assiut, Egypt. ${ }^{2}$ Department of Radiology, Taibah University, Medina, Saudi Arabia. ${ }^{3}$ Department of Pathology, Assiut University, Assiut, Egypt. ${ }^{4}$ Department of Public Health and Community Medicine, Cairo University, Cairo, Egypt. ${ }^{5}$ Department of Family and Community Medicine, Taibah University, Medina, Saudi Arabia.

Received: 29 March 2021 Accepted: 21 June 2021

Published online: 06 July 2021

\section{References}

1. WHO Pneumonia of unknown cause - China. WHO 2020 [cited 2021 Mar 3] Available from: http://www.who.int/csr/don/05-january-2020-pneumonia-ofunkown-cause-china/en/

2. WHO Unity studies: early investigation protocols. World Health Organization [cited 2021 Mar 3]. Available from: https://www.who.int/emergencies/disea ses/novel-coronavirus-2019/technical-guidance/early-investigations

3. Report S. 12 Feb COVID-19 name. 2020;2019. Available from: https://www. who.int/docs/default-source/coronaviruse/situation-reports/20200212sitrep-23-ncov.pdf?sfvrsn=41e9fb78_4

4. Chen N, Zhou M, Dong X, Qu J, Gong F, Han Y et al (2020) Epidemiological and clinical characteristics of 99 cases of 2019 novel coronavirus pneumonia in Wuhan, China: a descriptive study. Lancet [cited 2021 Mar 3];395(10223): 507-13. Available from: https://pubmed.ncbi.nlm.nih.gov/32007143/

5. Ren L-L, Wang Y-M, Wu Z-Q, Xiang Z-C, Guo L, Xu T et al (2020) Identification of a novel coronavirus causing severe pneumonia in human: a descriptive study. Chin Med J [cited 2021 Mar 4];133(9):1015-24. Available from: https://journals.Iww.com/10.1097/CM9.0000000000000722

6. Soyer P (2020) Lessons learned from chest CT in COVID-19. Vol. 101, Diagnostic and Interventional Imaging. Elsevier Masson SAS, pp 261-262

7. Carotti M, Salaffi F, Sarzi-Puttini P, Agostini A, Borgheresi A, Minorati D et al (2020 [cited 2020 Aug 19]. p. 636-46. Available from:) Chest CT features of coronavirus disease 2019 (COVID-19) pneumonia: key points for radiologists. Radiol Med 125. https://doi.org/10.1007/s11547-020-01237-4

8. Fang $Y$, Zhang H, Xie J, Lin M, Ying L, Pang P et al (2020 [cited 2021 May 29]. p. E115-7. Available from:) Sensitivity of chest CT for COVID-19: comparison to RT-PCR. Radiology 296. https://doi.org/10.1148/radiol.20202 00432

9. Koo HJ, Lim S, Choe J, Choi SH, Sung H, Do KH (2018 [cited 2021 Jan 12]. p. 719-39. Available from:) Radiographic and CT features of viral pneumonia. Radiographics 38. https://doi.org/10.1148/rg.2018170048

10. Zhu Z, Lian X, Su X, Wu W, Marraro GA, Zeng Y (2020) From SARS and MERS to COVID-19: a brief summary and comparison of severe acute respiratory infections caused by three highly pathogenic human coronaviruses. Respir Res 21 [cited 2021 Feb 6]. p. 224. Available from: https://respiratory-research. biomedcentral.com/articles/10.1186/s12931-020-01479-w

11. Cheng Z, Lu Y, Cao Q, Qin L, Pan Z, Yan F, Yang W (2020) Clinical features and chest CT manifestations of coronavirus disease 2019 (COVID-19) in a single-center study in Shanghai, China. AJR Am J Roentgenol 215(1):121126. https://doi.org/10.2214/AJR.20.22959

12. Hani C, Trieu NH, Saab I, Dangeard S, Bennani S, Chassagnon G et al (2020) COVID-19 pneumonia: a review of typical CT findings and differential diagnosis. Diagn Interv Imaging 101:263-268

13. Omar S, Motawea AM, Yasin R (2020) High-resolution CT features of COVID19 pneumonia in confirmed cases. Egypt J Radiol Nucl Med [cited 2020 Aug 19];51(1):121. Available from: https://ejrnm.springeropen.com/articles/10.11 86/s43055-020-00236-9

14. Pan F, Ye T, Sun P, Gui S, Liang B, Li L, Zheng D, Wang J, Hesketh RL, Yang $L$, Zheng $C$ (2020) Time course of lung changes at chest $C T$ during recovery from coronavirus disease 2019 (COVID-19). Radiology. 295(3):715-721. https://doi.org/10.1148/radiol.2020200370

15. Shi H, Han X, Jiang N, Cao Y, Alwalid O, Gu J, Fan Y, Zheng C (2020) Radiological findings from 81 patients with COVID-19 pneumonia in Wuhan, China: a descriptive study. Lancet Infect Dis 20(4):425-434. https://doi.org/1 0.1016/S1473-3099(20)30086-4 
16. Guan CS, Lv Z (2020) Bin, Yan S, Du YN, Chen H, Wei LG, et al. Imaging features of coronavirus disease 2019 (COVID-19): evaluation on thin-section CT. Acad Radiol 27(5):609-613. https://doi.org/10.1016/j.acra.2020.03.002

17. Li M, Lei P, Zeng B, Li Z, Yu P, Fan B et al (2020) Coronavirus disease (COVID-19): spectrum of $C T$ findings and temporal progression of the disease. Acad Radiol 27:603-608

18. Dai WC, Zhang HW, Yu J, Xu HJ, Chen H, Luo SP, Zhang H, Liang LH, Wu XL, Lei Y, Lin F (2020) CT imaging and differential diagnosis of COVID-19. Can Assoc Radiol J 71(2):195-200. https://doi.org/10.1177/0846537120913033

19. Bernheim A, Mei X, Huang M, Yang Y, Fayad ZA, Zhang N et al (2020) Chest C $T$ findings in coronavirus disease 2019 (COVID-19): relationship to duration of infection. Radiology 295:685-691

20. Hosseiny M, Kooraki S, Gholamrezanezhad A, Reddy S, Myers L (2020) Radiology perspective of coronavirus disease 2019 (COVID-19): lessons from severe acute respiratory syndrome and Middle East respiratory syndrome. Am J Roentgenol [cited 2020 Aug 21];214(5):1078-82. Available from: https://www.ajronline.org/doi/10.2214/AJR.20.22969

21. Franquet T (2011) Imaging of pulmonary viral pneumonia. Radiology 260: 18-39

22. Chen X, Zhang G, Hao S, Bai L, Lu J (2019) Similarities and differences of early pulmonary CT features of pneumonia caused by SARS-CoV-2, SARS-CoV and MERS-CoV: Comparison Based on a Systemic Review. Chin Med Sci J:1

23. Petrosillo N, Viceconte G, Ergonul O, Ippolito G, Petersen E (2020 [cited 2020 Aug 21];26:729-34. Available from:) Narrative review COVID-19, SARS and MERS: are they closely related? Clin Microbiol Infect. https://doi.org/10.1016/ j.cmi.2020.03.026

24. Henkel M, Weikert T, Marston K, Schwab N, Sommer G, Haslbauer J, Franzeck F, Anastasopoulos C, Stieltjes B, Michel A, Bremerich J, Menter T, Mertz KD, Tzankov A, Sauter AW (2020) Lethal COVID-19: radiologicalpathological correlation of the lungs. Radiol Cardiothorac Imaging [cited 2021 Jan 13];2(6):e200406. Available from: http://pubs.rsna.org/doi/10.1148/ ryct.2020200406

25. Scimeca M, Urbano N, Bonfiglio R, Montanaro M, Bonanno E, Schillaci O et al Imaging diagnostics and pathology in SARS-CoV-2-related diseases. Int J Mol Sci 21 MDPI AG; 2020 [cited 2021 Jan 13]. p. 1-22. Available from: www.mdpi.com/journal/ijms

26. Li B, Li X, Wang Y, Han Y, Wang Y, Wang C et al (2020) Diagnostic value and key features of computed tomography in coronavirus disease 2019. Emerg Microbes Infect 9:787-793

27. Bulgular ABT, Korelasyonu K (2020) Atypical CT findings and clinical correlation of COVID-19. 8(3):489-498

28. Gurumurthy B, Das SK, Hiremath R, Shetty S, Hiremath A, Gowda T (2021 [cited 2021 May 29];52(1):1-13. Available from:) Spectrum of atypical pulmonary manifestations of COVID-19 on computed tomography. Egypt J Radiol Nucl Med. https://doi.org/10.1186/s43055-021-00448-7

29. Salehi S, Abedi A, Balakrishnan S, Gholamrezanezhad A (2020) Coronavirus disease 2019 (COVID-19): a systematic review of imaging findings in 919 patients. AJR Am J Roentgenol 215(1):87-93. https://doi.org/10.2214/AJR.2 0.23034

30. Muheim M, Weber FJ, Muggensturm P, Seiler E (2020) An unusual course of disease in two patients with COVID-19: pulmonary cavitation. BMJ Case Rep 13(9)

31. Yao XH, Li TY, He ZC, Ping YF, Liu HW, Yu SC et al (2020) A pathological report of three COVID-19 cases by minimally invasive autopsies. Zhonghua bing li xue za zhi $=$ Chinese J Pathol [cited 2021 May 30];49:E009. Available from: http://www.ncbi.nlm.nih.gov/pubmed/32172546

32. Menter T, Haslbauer JD, Nienhold R, Savic S, Hopfer H, Deigendesch $\mathrm{N}$ et al (2020) Postmortem examination of COVID-19 patients reveals diffuse alveolar damage with severe capillary congestion and variegated findings in lungs and other organs suggesting vascular dysfunction. Histopathology [cited 2021 May 30];77(2):198-209. Available from: https://pubmed.ncbi.nlm. nih.gov/32364264/

33. Ye Z, Zhang Y, Wang Y, Huang Z, Song B (2020) Chest CT manifestations of new coronavirus disease 2019 (COVID-19): a pictorial review. Eur Radiol [cited 2021 May 30];30(8):4381-9. Available from: https://pubmed.ncbi.nlm. nih.gov/32193638/

34. Bradley BT, Bryan A (2019) Emerging respiratory infections: the infectious disease pathology of SARS, MERS, pandemic influenza, and Legionella. Semin Diagn Pathol 36 [cited 2021 Mar 3]. p. 152-9. Available from: https:// pubmed.ncbi.nlm.nih.gov/31054790/
35. Woodard PK (2021) Pulmonary thromboembolism in COVID-19. Radiology [cited 2021 Mar 3];298(2):E107-8. Available from: http://pubs.rsna.org/doi/1 $0.1148 /$ radiol.2020204175

36. Yang X, Yu Y, Xu J, Shu H, Xia J, Liu H et al (2020) Clinical course and outcomes of critically ill patients with SARS-CoV-2 pneumonia in Wuhan, China: a single-centered, retrospective, observational study. Lancet Respir Med [cited 2021 May 30];8(5):475-81. Available from: https://pubmed.ncbi. nlm.nih.gov/32105632/

37. Chan JFW, Yuan S, Kok KH, To KKW, Chu H, Yang J et al (2020 [cited 2021 May 30];395(10223):514-23. Available from:) A familial cluster of pneumonia associated with the 2019 novel coronavirus indicating person-to-person transmission: a study of a family cluster. Lancet. https://doi.org/10.1016/S014 $0-6736(20) 30154-9$

\section{Publisher's Note}

Springer Nature remains neutral with regard to jurisdictional claims in published maps and institutional affiliations.

\section{Submit your manuscript to a SpringerOpen ${ }^{\circ}$ journal and benefit from:}

- Convenient online submission

- Rigorous peer review

- Open access: articles freely available online

- High visibility within the field

- Retaining the copyright to your article

Submit your next manuscript at $\boldsymbol{\nabla}$ springeropen.com 